\title{
Accounting for the Response-Shift: Pre-Service Teacher-Efficacy Development in Immersive Learning
}

\author{
Winnie Mucherah ${ }^{*}$ and Kendra Edwards Thomas
}

\author{
Department of Educational Psychology, Ball State University, Muncie, IN 47306, USA
}

\begin{abstract}
This article compares the changes in efficacy of pre-service teachers in an immersive learning practicum and in a traditional practicum. It does not assume that pre-service teachers take the same pattern of development as inservice teachers because of the restructuring that must occur in an educational setting. The first study followed the development of 159 preservice teachers and found a significant interaction between the two groups across time in terms of teacher efficacy. The immersive group's efficacy increased significantly more than the control group. The second study assessed the response-shift of pre-service teachers between their pretests and their retrospective pretests. As hypothesized, the difference between the pretest and the retrospective pretest was greater for the immersive group compared to the control group, indicating the power that immersive experiences has to recalibrate the concept of teacher-efficacy. Implications for pre-service teacher education are discussed.
\end{abstract}

Keywords: Teacher-efficacy, response-shift bias, immersive learning, retrospective pretest, pre-service teacher.

This study aims to demonstrate the importance that immersive programs have on helping pre-service teachers mature their self-efficacy conceptualizations and deepen their grasp of the realistic challenges ahead. While there is much research about the importance of teacher efficacy in promoting positive student outcomes, we cannot assume that pre-service teachers have the same pattern of development as those with much experience in the field. This study will further the discussion of the purpose and realistic objectives for preservice teacher-efficacy development. While it is important that efficacy increase in the long run, a linear model does not account for the depth and restructuring that must occur in a preparatory setting so they may enter the field with an adequate framework.

\section{IMPORTANCE OF SELF-EFFICACY IN EDUCATORS}

Self-efficacy is the belief about personal competence or effectiveness in a given area. Bandura (1997) defines self-efficacy as "belief in one's capabilities to organize and execute the courses of action required to produce given attainments" (p. 3). A highly efficacious person is more likely to select challenging goals and experiences (Bandura, 1986). Although self-efficacy is not a substitute for talent or acquired skills, it is a very important mediator between skills and performance or subsequent skill acquisition (Bandura, 1986).

Interest in self-efficacy has led to the research and categorization of teacher efficacy: A teacher's belief in

*Address correspondence to this author at the Department of Educational Psychology, Ball State University, Muncie, IN 47306, USA; Tel: (765) 2858514; Fax: (765) 285-3653; E-mail: wmucherah@bsu.edu his or her capability to organize and execute courses of action required to successfully accomplish a specific task in a particular context (Tschannen-Moran, Hoy \& Hoy, 1998). A strong sense of teacher efficacy is related to student achievement (Hoy \& Woolfolk, 1993; Tschannen-Moran, Woolfolk Hoy \& Hoy, 1998; Woolfolk, Rosoff, \& Hoy, 1990), effective teaching (Hoy \& Woolfolk, 1990, 1993), increase in teacher effort (Bandura, 1986; Almog \& Shechtman, 2007), increased probability of employing a constructivist teaching approach (Temiz \& Tupeu, 2013), high student expectations and a higher sense of accountability (Ashton, 1985). Teachers with a high efficacy will work harder and persist longer when they face challenges because they are confident they can be overcome.

\section{TEACHER EFFICACY IN LOW-INCOME CONTEXTS}

An important distinction of teacher-efficacy is that it is, by nature, context-specific and does not necessarily transfer to alternate settings (Tschannen-Moran, Hoy \& Hoy, 1998). This helps explain why the differences among teachers' sense of efficacy are accentuated along the suburban-urban school divide (Hoy \& Spero, 2005; Knoblauch \& Hoy, 2008; Siwatu, 2011). In Siwatu's study (2011) preservice teachers reported feeling more prepared to teach in suburban contexts compared to urban contexts and those in urban school settings exhibited significantly lower efficacy (Siwatu, 2011). In another study, teachers in higher SES classrooms felt more supported and found their teaching assignment less difficult than teachers in lower SES classrooms (Hoy \& Spero, 2005). Compared to suburban assignments, urban student teachers also exhibited significantly lower perceived 
collective efficacy (Knoblauch \& Hoy, 2008) which is an important contributor to social change (Bandura, 1986).

The National Center for Education Statistics predicts the increase of minority students and the steady decrease of students who are White (NCES, 2013); however, the majority of the public school teachers are White (U.S. Department of Education, 2008) and more comfortable teaching in familiar settings. With a growing diverse population, many teachers will find jobs in settings with children of various ethnic backgrounds, many of whom will be different from the teachers' background (Eckert, 2013).

This mismatch between the teachers and students' backgrounds has dramatic implications for teacher efficacy development. Research suggests that teacher attrition (correlated with teacher efficacy) is highest in schools with a high percentage of low income, and minority students (Moon, 2007) and a high level of teacher turnover is a significant problem for many urban schools (Eckert, 2013; Taylor, 2009). Teachers who doubt their competency to manage daily classroom challenges are more likely to experience burnout, resulting often in a decision to leave the profession (Schawarzer \& Hallum, 2008; Skaalvik \& Skaalvik, 2007, 2010). Fostering teacher efficacy in low-income settings is vital for teacher continuity in schools.

One of the reasons self-efficacy in urban educational settings is lower is because of misconceptions and lack of experience in urban or diverse schools. Teacher education should strive to debunk these misconceptions and give teachers reallife experiences in urban contexts (Hampton, Peng \& Ann, 2008). Through more critical reflection and fieldbased experiences it is possible to change misconceptions of preservice teachers, but the task is great (Walker-Dalhouse \& Dalhouse, 2006). The current study follows the development of preservice teachers in both a traditional practicum as well as an immersive learning experience practicum that focuses on developing skills in diverse, low-income settings.

\section{DISTINGUISHING SELF-EFFICACY IN PREPARA- TORY SETTINGS}

Research in teacher education has reported that self-efficacy rises with academic preparation but falls with subsequent professional experience (Chester \& Beaudin, 1996; Hoy \& Spero, 2005). Perhaps this is because when novice teachers are confronted with the daily classroom challenges they deepen their concept of an efficacious teacher. That is not to say that this dip is a setback in their preparation, perhaps it is a vital part of their development and a sign of their maturing conceptualizations of the field. However, this dip poses a problem for teacher education programs. It is no use to focus on building teacher efficacy if it will fall within one year on the job. The understanding of this dip accentuates the need to research the process of development of teacher efficacy and the stability of this self-concept when transferring to a professional setting.

Although college can be a time of significant growth in self-efficacy (Zach, Harari \& Harari, 2012), measurement of self-efficacy can overlap with measurement of over-confidence (Moores \& Change, 2009; Vancouver, More \& Yoder, 2008; Vancouver, Thompson, Tischner \& Putka, 2002). Among undergraduate students, high self-efficacy was found to be positively related to current performance, but negatively related to later performance because it predicted over-confidence and poor allocation of resources (Moores \& Change, 2009). When selfefficacy is high due to task underestimation, students perform worse in future challenges. It is important to increase self-efficacy, but not at the expense of selfawareness.

While these finding may seem like a contradiction to the importance of teacher-efficacy development, it does not negate Bandura's theory. He proposed that weaker self-percepts are sensitive to new information and significant changes in task demands will prompt continued self-efficacy reappraisals. Thus, wider experiences permit better self-understanding which enables more accurate judgment of self-efficacy (Bandura, 1986). In preparatory situations, preservice teachers are still learning about the demands of the job and cannot accurately assess their efficacy. Discrepancies between self-efficacy and performance arise when people do not have a firm grasp of the complexities of the tasks ahead leading to faulty selfknowledge (Bandura \& Schunk, 1981) and highlight the fragility of self-efficacy in preparatory situations.

Recent studies in undergraduate settings concluded that self-efficacy perceptions can be easily influenced through the manipulation of their performance (Stone, 1994) or their priming prior to the task (Vancouver, Thompson, Tischner \& Putka, 2002). These findings highlight the importance of priming and preparing preservice teachers for their future challenges. Their priming will influence their expectations and 
interpretations of subsequent successes or failures. Moreover, the relationship between self-efficacy and performance is complex because individuals must perceive the task to be challenging enough to allocate resources and commit to the challenge (Vancouver, More \& Yoder, 2008).

Pointing out the dissonance between pre-service teachers' current state and their professional goals could be one of the most important things to propel healthy teacher efficacy (Rushton, 2000). Wheatly (2004) advocated that perceiving dissonance between current skills and required skills is vital to develop strong teacher efficacy in preservice teachers. Too much confidence can leave teachers with little reason to reflect on their practices thus perpetuating poor habits.

Understanding this pattern of development and the necessary threshold of challenge could be at the heart of developing resilient efficacy in educators. Spero and Hoy (2008) assessed prospective and novice teachers at the beginning of their preparation program, end of their student teaching and after their first year teaching. This longitudinal analysis concluded that teacher efficacy rose with preparation but declined with experience and those in lower SES classrooms were more at risk for a drop in efficacy. Similarly, Chester and Beaudin (1996) followed teachers that had been hired at an urban public school district and found that decline in self-efficacy in the first year of teaching is mediated by prior experience. Therefore, it is critical that teacher education programs provide the maximum amount of challenges and diverse experiences to build resilient self-efficacy.

In order to assess this development, we must move beyond a traditional pretest/posttest model. Assessing only two points inevitably creates a linear model. Instead, it is important that we account for the shift that occurs in their self-perception skills and analyze selfefficacy development while accounting for the response shift bias.

\section{ANALYZING RESPONSE SHIFT BIAS IN SELF- PERCEPTION}

Perhaps the key to quantitatively assess the depth of change in self-perceived efficacy is to tap into the instrumentation effect called response-shift bias. Howard (1979) first coined this term when he observed that retrospective pretests were more in line with the ratings of independent judges than true pretests. He concluded that exposure to training causes the individual to reassess how they measure themselves because of their exposure to new challenges and circumstances. This internal metric shift was coined response-shift bias and explains how actual changes in knowledge and behaviors from pretest to posttest may be masked if the participants overestimate their knowledge and skills on the pretest. When responseshift bias is present, sometimes the inclusion of a retrospective pretest produces a more legitimate assessment (Coulter, 2012; Howard, 1979; Pratt, McGuigan \& Katzev, 2001; Sibthorp, Paisley, Gookin \& Ward, 2007).

This response-shift occurs when people do not have all the information they need to make accurate selfjudgments (Dunning, Heath, \& Suls, 2004; Moore \& Tananis, 2009). In educational settings, when students do not yet have the experience necessary to assess themselves, they are vulnerable to overestimating their knowledge on the pretest. Researchers often assume the participants' internal scale of self measurement will be consistent (Moore \& Tananis, 2009; Sibthorp et al., 2007). To address this assumption, researchers must have some way to account for the recalibration of internal metrics. Much research on teacher efficacy in the past has been generalized to pre-service teachers. However, if pre-service teachers have weaker selfprecepts, they are more vulnerable to the circumstances around them because they are still solidifying their understanding of the challenges of teaching. Thus, research on in-service teacher efficacy should not be blindly generalized to pre-service teachers because their understanding of the challenges is not yet stable.

Measuring development only using retrospective pretests and posttests expose the research to fundamental vulnerabilities. However, self-perceived variables such as self-efficacy, are highly susceptible to modification of the participants' internal metric system due to outside variables (Sibthorp et al., 2007), thus utilizing only a pretest-posttest model is insufficient. It is important to measure longitudinal development of some constructs with a pretest, a posttest and a retrospective pretest. In this model, the goal is not to prove which type of pretest is more accurate; the goal is to measure the shift and include it in the framework of development. Measuring this response shift is especially important for socially oriented constructs (such as teacher efficacy) because these are more vulnerable to the response-shift bias than objective questions that have more consistent internal metrics (Sibthorp et al., 2007). 
Failure to measure this shift could lead to a Type II error (Coulter, 2012; Leyser, Zeiger \& Romi, 2011; Sibthorp et al., 2007; Onen \& Kaygsiz, 2013). For example, Onen and Kaygisiz (2013) measured forty primary science education students in their third year and found no significant difference in their self-efficacy throughout three semesters. However, qualitative data reported increased teacher efficacy. Through interviews participants noted that, after taking their first practicum class, they realized their need for increased knowledge and experience in the field. Similarly, Sibthorp et al. (2007) asked students to assess their outdoor leadership abilities and found a significant response-shift in the quantitative assessment which was confirmed through qualitative research.

Powerful experiences that help students restructure their perceptions of reality serve an irreplaceable educational purpose. Perhaps one of the goals in a practicum is to help students improve their selfperception in order to motivate future growth. Teacherefficacy is contextually based and requires a substantial amount of social experience in classroom settings to grasp the depth of this challenge. Inclusion of the retrospective pretest along with the true pretest accounts for this recalibration of their internal metrics.

\section{IMMERSIVE LEARNING AND RESPONSE-SHIFT}

Efficacy development among preservice teachers is vulnerable to many experiences that could prompt a shift in their internal metrics. Because of this reality, the quality of educational experiences and the level of immersion each preservice teacher experiences will influence the depth of their response-shift. According to Bandura, strong self-percepts are changeable only through compelling disconfirmation and powerful negating experiences (1986). He emphasizes that it is the potency of the intervening experience, not the time elapsed, that shapes and changes self-percepts. If this is true, the level of immersion of a practicum experience will influence the change in teacher-efficacy and the amount of change in the internal metric system of each participant. Actively creating this dissonance is an essential part of teacher development which can lead to greater growth overall (Wheatley, 2004) and possibly act as the "powerful negating experiences" that prompt change.

Contrary to the statistics about in-service teachers' lower efficacy in low-income schools, Knoblauch \& Hoy (2008) were surprised to report that urban studentteachers' efficacy increased across one semester of student teaching. They concluded this growth was because the student-teachers successfully handled a more complex and challenging situation. This experience allowed them to wrestle with the dissonant situation while still receiving the support of their faculty mentors. These findings are in line with the importance of challenging preservice teachers with contextual difficulties. Too often education is in a massed training setting which enables the processing of a large amount of content but leaves students overconfident and their knowledge untested. The key is to introduce "desirable difficulties" to slow down the speed of learning and help process, retain, apply and transfer content (Dunning, Heath \& Suls, 2004). Immersive learning introduces those difficulties thus creating a powerful agent for change in self-assessment.

Research has evidenced that teacher-efficacy can rise in preparatory settings but fall shortly after entering a professional setting (Chester \& Beaudin, 1996; Hoy \& Spero, 2005). Perhaps this trend can be altered through more immersive experiences in teacher education. Exposure to challenging situations will help preservice teachers re-assess their self-efficacy and strengthen it thus inoculating them from a vulnerable efficacy in their first job.

This study will attempt to provide empirical support for the power that immersive experiences have to recalibrate the internal metrics of teacher-efficacy and further its development in preservice teachers.

\section{METHOD}

\section{Community-Based Immersive Learning (CBIL) Program}

CBIL is a program designed by an interdisciplinary group of faculty representing elementary education, early childhood education, educational foundations, and educational psychology, in collaboration with a local school and community. This is a new program within a Midwestern university's teachers college that addresses the needs of preservice teachers and the surrounding community. The CBIL program removes candidates entirely from campus and immerses them in a community setting for an entire semester's coursework. The purpose of the interdisciplinary, immersive semester is to provide a new approach to preparing early childhood and elementary school teachers - an approach that introduces and incorporates future teachers into the complex interplay of factors that influence children's learning. 
Integral to candidates' experience throughout the semester is a practicum placement in an early childhood program or elementary school serving primarily low-income, minority children and families. Candidates spend ten hours per week in their placement site, participating in classroom life, and experiencing school culture. They plan and teach lessons under the guidance of a cooperating teacher, and participate in parent teacher conferences and additional family engagement activities. When they are not at their practicum placement sites, candidates meet at the local community center, where they receive content from faculty and learn from community members the richness of children's lives outside of school. At least one day per week, candidates plan and implement enrichment experiences for children who attend the after school program at the community center. The center affords additional opportunities to participate in a variety of programs, which include sports and recreation, a women's oral history project, neighborhood community council meetings, and other community and family gatherings taking place throughout the semester.

Throughout the semester, strengths and weaknesses of the community surrounding the school are fully explored through the lived history of its residents. Preservice teachers are charged with uncovering these "funds of knowledge" (Moll, Amanti, Neff, \& Gonzalez, 1992) that are the foundations from which children come and upon which their future learning can be built. Such "discourse of lived cultures" (Giroux, 1997) provides "an understanding of how [community members] give meaning to their lives through complex historical, cultural, and political forms that they both embody and produce" (p. 140). In the CBIL program, the intellectual, social, and emotional capital of communities (Apple, 1996) is emphasized as a critical consciousness in developing the relationships integral to successful teaching.

Curriculum throughout the semester is integrated in order to provide a seamless experience, instead of discreet "courses." Content is organized around themes, including: school, family, and community relations; child development within the context of community; diversity; planning for instruction; and knowledge about the community. Content is delivered in multiple contexts, by multiple "knowers" throughout the community (Singleton \& Linton, 2006), broadening the definition of "teacher educator" beyond university faculty to include school administrators, local pastors, service providers, community elders, members of the local community council, and family members within the community.

Each candidate is assigned a community mentor who serves as a cultural ambassador throughout the semester. Along with their mentors, candidates attend church services and other family and community events, gaining additional perspective and experience with children's lives outside of school and the values of families within the community. Also, candidates occasionally invite their mentor to campus events. Instead of passive observation, which is characteristic of university students' experience in cultural communities, the mentor/candidate relationship affords the opportunity for authentic participation in community life, leading candidates toward "cultural interpretation," which is key to their understanding of, and subsequent participation in, the community (Wolcott, 1987). This model provides the vehicle through which the typical "outside-in" view of a cultural community can be transformed.

Opportunities to reflect and interpret experiences are critically connected to candidate growth throughout the semester. Weekly written reflections provide a personal conversation between candidates and program faculty, and daily opportunity to process observations and interactions allow the time and space to wrestle with the disequilibrium that is a frequent response to novel "encounters" (Gay, 1985). A weekly "courageous conversation" (Singleton \& Linton, 2006) is structured between all students and program faculty, providing time and a safe environment for the deconstruction of prior schema relative to new experience. Throughout the semester faculty focus on negotiation of such experiences and strive to move candidates toward the construction of a new lens through which to view teaching and learning.

The elementary school where the CBIL preservice teachers were placed is a school in which $95 \%$ of the children are eligible for the free and reduced lunch program. It was also a school that had been identified as "In Need of Improvement" under the No Child Left Behind Act. This American legislation encompasses numerous federal education programs for testing and accountability of schools. If schools fail to make adequate yearly progress according to state government standards for two consecutive years they are considered "In Need of Improvement". The early childhood center was a nationally accredited program serving low-income children and families, with $90 \%$ qualifying for free and reduced lunch. The Head Start 
program, a federal program to promote school readiness from birth to age five, served exclusively lowincome families. The CBIL group was in the school or early childhood center ten hours per week for twelve weeks, and were assigned to one classroom under the direction of one teacher. Throughout the semester, they developed and taught lessons to students in their classrooms. Note: this program description has been used in a previously published paper (X \& X, 2014).

\section{Control group}

The control group completed their field experience at the University Laboratory School on the University campus. Preservice teachers in the control group were placed in an elementary (K-5) classroom three hours and forty minutes per week for nine weeks (total 33 hours), where they engaged in activity similar to the immersive group. Candidates in the control group engaged in a one hour seminar experience each day following their practicum experience, through which they shared their experience and explored topics relative to teaching in the elementary school. Demographics of the University Laboratory School indicate a free and reduced lunch rate of $27.5 \%$ (2011). It is also noteworthy that the Laboratory School student body is admitted via a lottery system available to individuals throughout the state, therefore representing geographic as well as economic diversity, in contrast to the immersive group, who share a common community. Note: Data used in a previous study (X \& X, 2014).

\section{Measures}

Teachers' Sense of Efficacy Scale- is a 12-item instrument that was developed by Tschannen-Moran and Hoy $(1998,2001)$ to measure teachers' sense of efficacy. The Teachers' Sense of Efficacy Scale assesses three major domains of teacher efficacy; Efficacy in Student Engagement, Efficacy in Instructional Practices, and Efficacy in Classroom Management. The Student Engagement domain measures teachers' perceptions of their ability to motivate their students and help them to value learning. The Instructional Practices domain assesses teachers' perceptions of their ability to craft good questions, use a variety of assessment strategies, and provide alternative explanations or examples for their students. Finally, the Classroom Management domain assesses teachers' perception of their ability to control disruptive behavior in the classroom and get their students to follow classroom rules.
Each of these three domains has 4 questions. The domains and original alphas are Engagement (e.g., "How much can you do to help your students value learning?", $\alpha=.81$ ), Instruction (e.g., "How much can you use a variety of assessment strategies?", $\alpha=.86$ ), and Classroom management (e.g., "How much can you do to control disruptive behavior in the classroom?", a $=.86)$. All questions are presented on a 9-step Likert continuum (e.g., 1= "Nothing" to $9=$ "A Great Deal"), with higher scores representing the high end of the domain.

\section{Reliability and Validity}

This scale has been used in teacher efficacy studies with preservice and practicing teachers (TschannenMoran, Hoy \& Hoy, 1998; Tschannen-Moran \& Hoy, 2001 ), and has proven to be reliable and valid. A testretest reliability of individual scores on domains, when administered twice with a six-week interval between occasions, ranged from .92 for Instruction to .94 for Classroom Management (Tschannen-Moran \& Hoy, 2001). Traditionally, this scale has been used to assess teacher efficacy mostly in traditional teacher preparation programs. Therefore, there was a need to determine if the internal consistency reliabilities of the domains in the present study were comparable to the original scale. To this end the Cronbach's alpha values were calculated for the three domains. The reliability alphas for the Immersive Learning Group were between .78 and .86 , while those for the control group were between .89 and .90 . Reliabilities are presented in Table 1.

Table 1: Reliability Analysis: Cronbauch's Alpha

\begin{tabular}{|c|c|c|}
\hline & Immersive & Control \\
\hline \hline Engagement & 0.862 & 0.894 \\
\hline Management & 0.789 & 0.892 \\
\hline Instruction & 0.815 & 0.903 \\
\hline
\end{tabular}

\section{Study 1}

\section{Participants}

The participants in the study were 159 undergraduate students who were majoring in either early childhood or elementary education at a Midwestern university. Fifty-two students were in the CBIL which will be referred to as the immersive group, and 107 were based on campus, who will be referred to as the control group. There were a total of 17 males, four in the immersive group and thirteen in the control 
Table 2: Participants 2011-2013: Study 1

\begin{tabular}{|c|c|c|c|}
\hline & N & Sex & Year \\
\hline \hline Control Group & 107 & 13 males & 1 sophomore 29 juniors 78 seniors \\
\hline Immersive Group & 52 & 4 males & 2 sophomores 41 juniors 9 seniors \\
\hline
\end{tabular}

group. This reflects, to a great extent, the overwhelming presence of mainly white, female teacher candidates in the teacher preparation program in elementary and early childhood education. See Table 2 for more information. All participants were completing their practicum experience at either a local elementary school or at the early childhood center or the nearby Head Start program.

\section{Analysis}

Data from fall 2011, fall 2012, and fall 2013 was combined to understand the overall impact the program has had in the past three years and between the immersive and control groups. Descriptive statistics were computed to determine the pattern throughoutthe semester and between groups. A between groups repeated measures ANCOVA was conducted between the immersive and the control group on their pretest and posttest scores on all three domains of teacher efficacy. Year in school was entered as a control variable since there were more seniors in the control group. Year in the program $(2011,2012,2013)$ was entered as a control variable to control for any minor differences in the program across the three years; no major differences were anticipated.

\section{Results}

Results from a descriptive analysis revealed that the means from the pretests and the posttests increased in the immersive group in the area of Engagement (pretest $M=7.29, S D=1.03$ to posttest $M=7.83$, $\mathrm{SD}=.79$ ), Management (pretest $\mathrm{M}=6.96, \mathrm{SD}=1.03$ to posttest $\mathrm{M}=7.76, \mathrm{SD}=.72$ ), and Instruction (pretest $M=6.99, S D=1.18$ to posttest $M=7.91, S D=.75$ ), but remained relatively the same in the control group in the area of Instruction (pretest $M=7.76, S D=.86$ to posttest $\mathrm{M}=7.85, \mathrm{SD}=.72$ ), Engagement (pretest $\mathrm{M}=7.64$, SD $=.99$ to posttest $\mathrm{M}=7.69, \mathrm{SD}=.87$ ), and Management (pretest $\mathrm{M}=7.78, \mathrm{SD}=.89$ to posttest $\mathrm{M}=7.74, \mathrm{SD}=.81$ ). It is also important to note that the immersive group had lower pretests than the control group on all three domains (engagement, management and instruction) but the immersive group had higher posttests than the control group in all areas. The imbalanced pretests could be because the control group contained a higher proportion of seniors and they were anticipating a more familiar environment.

In the between groups repeated measures ANCOVA the equality of covariance assumption was tested through the Box's M test and found insignificant ( $p>.05)$; therefore, it was not violated. There was a significant interaction between the groups across time (pretest to posttest) in the areas of Engagement $F(1$, $156)=10.79, p=.002$, Management $F(1,156)=26.67$, $p=.000$, and Instruction $F(1,156)=22.28, p=.000$. See Table 3 for more information on effect sizes and main effects. This indicates that the immersive group grew significantly more across the semester than the

Table 3: Teacher Efficacy Between Groups Repeated Measures

\begin{tabular}{|c|c|c|c|c|}
\hline & & $F$ & p & $\eta^{2}$ \\
\hline \multirow{3}{*}{ Engagement } & Time & .007 & .933 & 0.000 \\
\hline & Group & 0.368 & .545 & 0.002 \\
\hline & Time * Group & 10.79 & .002 & 0.063 \\
\hline \multirow{3}{*}{ Management } & Time & .878 & .350 & 0.006 \\
\hline & Group & 10.864 & .001 & 0.065 \\
\hline & Time * Group & 25.67 & .000 & 0.142 \\
\hline \multirow{3}{*}{ Instruction } & Time & .200 & .655 & 0.001 \\
\hline & Group & 8.832 & .003 & 0.054 \\
\hline & Time * Group & 22.28 & .000 & 0.126 \\
\hline
\end{tabular}

${ }^{*} p<.05{ }^{* *} p<.01{ }^{* * *} p<.001$; Time refers to the pretest-posttest main effect; Group refers to the Control group-Immersive Group main effect; Time ${ }^{*}$ Group refers to the interaction effect. 


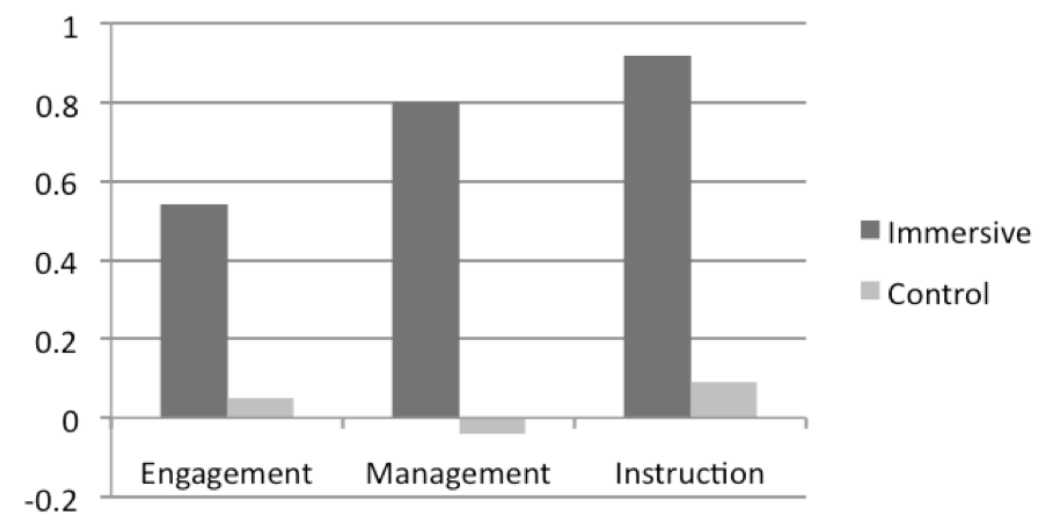

Graph 1: Difference (posttest minus pretest) between Immersive and Control group.

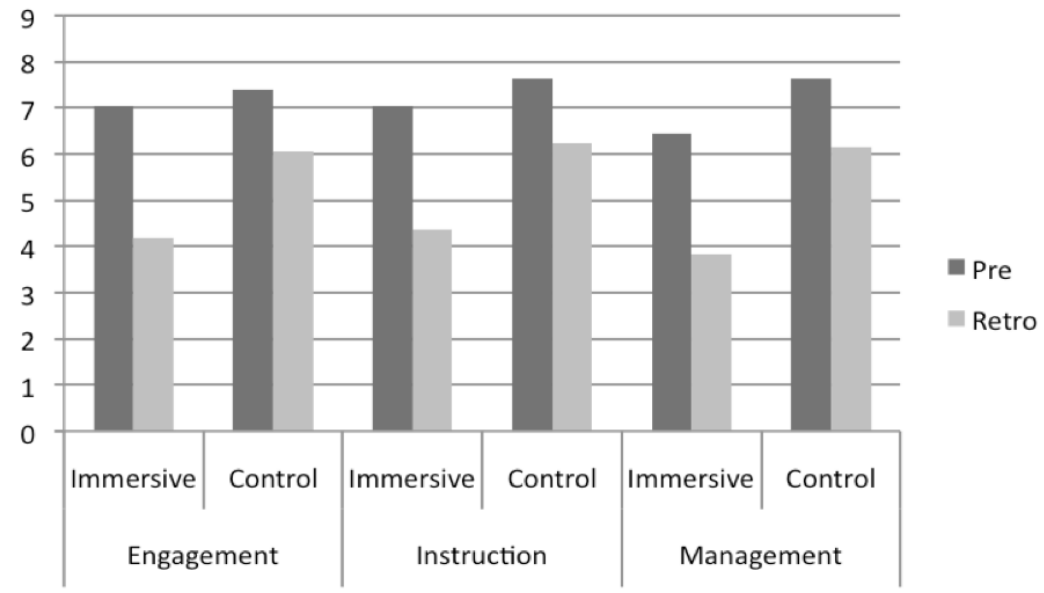

Graph 2: Pretest and Retrospective pretest of Immersive and Control groups.

control group in all three domains of teacher efficacy even after controlling for the effects of year in school and year in the program. See Graph 1 for a visual representation of the difference between groups.

\section{Study 2}

The purpose of this study was to account for the response shift bias that could have confounded results in the pretest-posttest methodology of Study 1. Through the use of the retrospective pretest it is possible to account for the shift and compare the shift between the immersive group and the control group.

After students took the posttest, they were given the same questions in a retrospective pretest format. For example, the question "How much can you do to get children to follow classroom rules?" was reworded to, "BEFORE this semester began, how much could you get children to follow classroom rules?"

Since the students took the pretest at the very beginning of the semester, and past research has shown that individuals do not recall initial pretest scores (Sibthorp et al., 2007), it is expected that the participants did not consciously base their posttest or retrospective results on their reported pretest scores.

\section{Participants}

The participants of this study are a subgroup from the participants in the previous group. These reflect only the fall 2013 pre-service teachers. There were 63 students total, 43 from the control group and 20 from the immersive group. Of these, only seven were male with six of these in the control group and one in the immersive group. Similar to Study 1, the control group was composed of mostly seniors (38 of 43 ) while the immersive group had primarily juniors (17 of 20). See Table 4 for more information.

\section{Analysis}

Descriptive statistics were computed to determine the patterns between groups on their pretests and 
Table 4: Participants 2013: Study 2

\begin{tabular}{|c|c|c|c|}
\hline & N & Sex & Year \\
\hline \hline Control Group & 43 & 6 males & 1 sophomore 3 juniors 38 seniors \\
\hline Immersive Group & 20 & 1 male & 17 juniors 3 seniors \\
\hline
\end{tabular}

retrospective pretests in all three areas of teacher efficacy.

A MANCOVA was conducted between the two groups on the retrospective shift of all three domains (Management, Instruction, and Engagement). The shift was considered the difference between the true pretest and the retrospective pretest. A MANCOVA was chosen because of the importance of taking all aspects of teacher efficacy into account when analyzing the differences in both groups. Year in school was entered as a control variable to account for the unequal distribution of seniors. To assess the assumptions of the MANCOVA, the Box's M test was conducted and determined to be not significant $(p>.05)$ indicating that the covariance matrices are considered equal across groups and the assumption is met.

\section{Results}

Descriptive statistics revealed that both groups selfrated lower in the retrospective pretest compared to their true pretest results in all three areas. However, the control group rated themselves higher in the retrospective pretest (Engagement $M=6.12, S D=.19$; Management $M=6.22, S D=.18$; Instruction $M=6.31$, $\mathrm{SD}=.19$ ) than the immersive group (Engagement $\mathrm{M}=4.17, \quad \mathrm{SD}=.28 ; \quad$ Management $\mathrm{M}=3.82, \quad \mathrm{SD}=.26$; Instruction $\mathrm{M}=4.37, \mathrm{SD}=.28$ ). See Table 5 for details.

As hypothesized, the difference between the pretest and the retrospective pretest was greater in the immersive group compared to the control group. There was a significant difference between the control group and the immersive group $F(1,60)=8.76 ; p=.000$, with a small effect size $\left(\Pi^{2}=.312\right)$. A descriptive discriminant analysis was used as a follow-up to this analysis. The value of .4 was used as a cut off to identify values that are important to the group difference. Instruction $(r=.477)$, Management $(r=.727)$ and Engagement $(r=.928)$ all were interpreted to be important contributors to the distrinction between the control group and the immersive group with Engagement contributing the most to the difference.

\section{DISCUSSION}

Results from the first study revealed that there was no statistically significant difference between the immersive group and the control group across time in the domains of Management, Instruction, or Engagement. It is notable that the control group started out higher than the immersive group and that they ended the semester on similar levels. We hypothesize that the control group started out higher because they were anticipating a more familiar environment. Selfefficacy is domain-specific and each group was filling out the questionnaire in light of different scenarios of teaching and this likely influenced the discrepancy at the beginning.

Teacher efficacy is especially important in lowincome and minority educational settings (Hoy \& Woolfolk, 1993; Tschannen-Moran, Hoy \& Hoy, 1998; Woolfolk, Rosoff, \& Hoy, 1990). Teachers who do not believe they have the competency to affect change are less likely to persevere and positively impact student achievement (Hoy \& Woolfolk, 1990, 1993; TschannenMoran, Hoy \& Hoy, 1998; Woolfolk, Rosoff, \& Hoy, 1990; Bandura, 1986; Almog \& Shechtman, 2007). Low teacher efficacy is especially associated with lowincome and high-minority setting (Eckert, 2013),

Table 5: Descriptive Statistics of Pretest and Retrospective Pretest

\begin{tabular}{|c|c|c|c|c|c|c|}
\hline \multirow{2}{*}{} & \multicolumn{3}{|c|}{ Immersive } & \multicolumn{3}{c|}{ Control } \\
\cline { 2 - 7 } & Pretest & Retrospective & Shift & Pretest & Retrospective & Shift \\
\cline { 2 - 7 } & $\mathbf{M}($ SD) & M (SD) & M (SD) & M (SD) & M (SD) & M(SD) \\
\hline \hline Engagement & $7.05(.23)$ & $4.17(.28)$ & $2.88(1.19)$ & $7.44(.16)$ & $6.12(.19)$ & $1.32(1.14)$ \\
\hline Management & $6.45(.21)$ & $3.82(.26)$ & $2.62(.97)$ & $7.64(.14)$ & $6.22(.18)$ & $1.42(1.22)$ \\
\hline Instruction & $6.60(.22)$ & $4.37(.28)$ & $2.23(1.35)$ & $7.65(.15)$ & $6.31(.19)$ & $1.34(1.25)$ \\
\hline
\end{tabular}


indicating that our significant increase in the immersive group is even more notable because of its scarcity in such environments.

The second study revealed the fluid nature of selfefficacy in preparatory settings and revealed the response-shift of participants. As expected, the immersive group had a significantly larger shift than the control group. This difference is attributed to the nature of the immersive learning program, its level of contact with the community, and the chance pre-service teachers get to interact meaningfully with an unfamiliar environment. The follow-up descriptive discriminant analysis revealed that all three domains (Engagement, Management, and Instruction) were important for differentiating the retrospective shift of the two groups, but Engagement and Management particularly drove the conceptual redefinition. The students in the immersive learning program deepened their understanding of what it means to engage students of diverse backgrounds and manage classrooms in different settings.

We advocate that the significant shift that the immersive learning students experienced will benefit them long-term. Prior research has shown that preservice teachers in a new setting (such as an innercity school) go through a transition period before they can develop a stable sense of efficacy (Rushton, 2000). This immersive program begins to familiarize preservice teachers with the complexities of the classroom and allows them to see the students from a holistic viewpoint through engaging with their families and communities. This initially unfamiliar experience helps inoculate them from the transition they will face upon graduation. The unfamiliarity is validated through their response-shift between pretest and retrospective pretest. The immersive group acknowledged that there was much more to learn and likely expanded their perspective compared to the control group.

While lower levels of teacher efficacy are often associated with urban schools because teachers are unfamiliar and underprepared (Eckert, 2013), they are not necessarily universal among urban schools. Supervisor observations are positively associated with self-efficacy (Chester \& Beaudin, 1996). The immersive learning program provides a high level of interaction with a cohort of students, supervising teachers, community mentors, and a low faculty-student ratio $(5: 1)$ across the semester. This training allows them to grapple with the new environment and the real-life challenges of teaching while still receiving the support of their mentors and supervisors.

While follow-up research is yet to be conducted to analyze the long-term impacts of this program, it is anticipated that students' deep interactions with the community helped foster a deep-seated growth that is seen both in real-time and in retrospect. The retrospective shift that is accentuated in the immersive group validates that students not only strengthened their teacher-efficacy but successfully expanded their horizons of what it means to be a competent teacher in multiple environments.

\section{CONCLUSION}

Teacher efficacy in preparatory settings must be differentiated from literature on in-service teacher efficacy. Students in teacher education programs have not yet acquired the breadth of experience that seasoned teachers have and cannot accurately measure their competencies in realistic work settings. It is no use for teacher education programs to focus on development of high teacher efficacy if the efficacy will drop within the first year of teaching (Chester \& Beaudin, 1996; Spero \& Hoy, 2008). Therefore, it is important that we understand the process of teacher efficacy development in preparatory settings and how to foster resilient teacher efficacy.

We propose that carefully planned immersive learning experiences can have a powerful effect on building self-efficacy. When students are provided impactful immersive experiences and a strong level of support they can adequately measure themselves in respect to the challenges they will face. They will inevitably learn about the challenges. However, if given the chance to explore the challenges and engage in unfamiliar environments while still in college, they can benefit from the support of a higher education learning community.

\section{LIMITATIONS AND FUTURE STUDIES}

The purpose of this study was to understand the shift in self-perception of teacher-efficacy among preservice teachers. This study does not claim that retrospective pretests are more accurate than true pretests, simply that the differences between them are relevant in understanding self-efficacy development in preparatory settings.

Retrospective pretests are not without their own biases. Retrospective questionnaires can be 
susceptible to effort justification bias and selfenhancement bias (Taylor, Russ \& Taylor, 2009). In other words, participants may be biased to portray growth in order to justify their efforts. However, if that is the only phenomenon occurring, the immersive group and the control group would have reported similar shifts.

Because of the complex nature of immersive programs, the sample sizes are unequal and come from only one university. There is need for future studies including multiple teacher education programs to further validate these findings. It is also important to note that participation in the immersive study was voluntary and therefore the groups do not represent randomized samples. However, the participants serve as their own control in the longitudinal analysis and the changes seen across time in this study are self-evident.

Future research should be conducted to further differentiate teacher-efficacy in preparatory settings from teacher-efficacy in established professionals. As individuals learn more about the challenges at hand, they can appropriately change their self-perceived competencies. This understanding has the potential to account for Type II errors seen in past research as well as understand that a temporary dip in efficacy might be a sign of maturation, not relapse.

Finally, the next step is to do a follow-up study on the self-efficacy of preservice teachers who have graduated from the immersive program and are now teaching. It is important to investigate if these changes are long-lasting and withstand the challenges of different environments and be resilient to the predicted efficacy decrease in the first year.

\section{REFERENCES}

Almog, O., \& Shechtman, Z. (2007). Teachers' democratic and efficacy beliefs and styles of coping with behavioural problems of pupils with special seeds. European Journal Of Special Needs Education, 22(2), 115-129. http://dx.doi.org/10.1080/08856250701267774

Ashton, P. (1985). Motivation and teacher's sense of efficacy. In C. Ames \& R. Ames (Eds.), Research on motivation in education: The classroom milieu (2), pp. 141-174. Orlando, FL: Academic Press

Bandura, A. (1997). Self-efficacy: The exercise of control. New York: Freeman.

Bandura, A. (1986). Social Foundations of Thought and Action: A Social Cognitive Theory. Englewood Cliffs, NJ: Prentice-Hall.

Bandura, A. \& Schunk, D. H. (1981). Cultivating competence, selfefficacy and intrinsic interest through proximal selfmotivation. Journal of Personality and Social Psychology, 41(3), 586-598.

http://dx.doi.org/10.1037/0022-3514.41.3.586
Chester, M.D., \& Beaudin, B. Q. (1996). Efficacy Beliefs of Newly Hired Teachers in Urban Schools. American Educational Research Journal, 33(1), 233-257. http://dx.doi.org/10.3102/00028312033001233

Coulter, S.E. (2012). Using the retrospective pretest to get usable, indirect evidence of student learning, Assessment \& Evaluation in Higher Education, 37(3), 321-334. http://dx.doi.org/10.1080/02602938.2010.534761

Dunning, D., Heath, C., \& Suls, J. M. (2004). Flawed SelfAssessment: Implications for Health, Education, and the Workplace. Psychological Science in the Public Interest, 5(3), 69-106. http://dx.doi.org/10.1111/j.1529-1006.2004.00018.x

Eckert, S. (2013). What Do Teaching Qualifications Mean in Urban Schools? A Mixed-Methods Study of Teacher Preparation and Qualification. Journal Of Teacher Education, 64(1), 7589.

http://dx.doi.org/10.1177/0022487112460279

Gay, G. (1985). Implications of selected models of ethnic identity development for educators. Journal of Negro Education, 54(1), 43-55.

http://dx.doi.org/10.2307/2294899

Giroux, H. A. (1997). Pedagogy and the politics of hope: Theory, culture, and schooling. Boulder, CO: Westview Press.

Hampton, B., Peng, L., \& Ann, J. (2008). Pre-service Teachers' Perceptions of Urban Schools. Urban Review, 40(3), 268295. http://dx.doi.org/10.1007/s11256-008-0081-2

Howard, G. (1979). Response-shift bias: A source of contamination of self-report measures. Journal of Applied Psychology, 64 (2), 144-150. http://dx.doi.org/10.1037/0021-9010.64.2.144

Hoy, A. W. \& Spero, R. B. (2005). Changes in teacher efficacy during the early years of teaching: A comparison of four measures. Teaching and Teacher Education, 21, 343-356. http://dx.doi.org/10.1016/j.tate.2005.01.007

Hoy, W.K., \& Woolfolk, A.E. (1993). Teachers' sense of efficacy and the organizational health of schools. Elementary School Journal, 93, 355-372. http://dx.doi.org/10.1086/461729

Hoy, W.K., \& Woolfolk, A.E. (1990). Organizational socialization of student teachers. American Educational Research Journal, 27, 279- 300 . http://dx.doi.org/10.3102/00028312027002279

Knoblauch, D. \& Hoy, W. A. (2008). "Maybe I can teach those kids". The influence of contextual factors on student teachers efficacy beliefs. Teaching and Teacher Education, 24(1), 166-179.

http://dx.doi.org/10.1016/j.tate.2007.05.005

Leyser, Y., Zeiger, T. \& Romi, S. (2011). Changes in self-efficacy of prospective special and general education teachers: Implications for inclusive education. International Journal of Disability, Development and Education, 58(3), 241-255. http://dx.doi.org/10.1080/1034912X.2011.598397.

Moll, L. C., Amanti, C., Neff, D., \& Gonzalez, N. (1992). Funds of knowledge for teaching: Using a qualitative approach to connect homes and classrooms. Theory into Practice, 31(2), 132-141. http://dx.doi.org/10.1080/00405849209543534

Moon, B. (2007). Research analysis: Attracting, developing and retaining effective teachers: A global overview of current policies and practices. Paris, France: United Nations Educational, Scientific, and Cultural Organization.

Moore, D. \& Tananis, C.A. (2009). Measuring change in a short-term educational program using a retrospective pretest design. American Journal of Evaluation, (30)2, 189-202. http://dx.doi.org/10.1177/1098214009334506

National Center for Education Statistics (2013). Projections of Education Statistics to 2021. Washington, DC: Institute of 
Education Science, U.S. Department of Education. http://nces.ed.gov/programs/projections/projections2021/sec 1a.asp

Onen, F., \& Kaygisiz, G. M. (2013). Prospective science teachers' self-efficacy beliefs about teaching science between 6-7 8terms and the opinions on these beliefs. Educational Sciences: Theory \& Practice, 13(4). 2449-2453.

Pratt, C.C., McGuigan, W.M., \& Katzev, A.R. (2001). Measuring Program Outcomes: Using Retrospective Pretest Methodology, 21(3), 341-349.

Rushton, S. P. (2000). Student teacher efficacy in inner-city schools. The Urban Review, 32(4), 365-383. http://dx.doi.org/10.1023/A:1026459809392

Schwarzer, R., \& Hallum, S. (2008). Perceived teacher self-efficacy as a predictor of job stress and burnout: Mediation analyses. Applied Psychology: An International Review, 57152-171. http://dx.doi.org/10.1111/j.1464-0597.2008.00359.x

Sibthorp, J., Paisley, K., Gookin, J., \& Ward, P. (2007). Addressing response-shift bias: Retrospective pretests in recreation research and evaluation. Journal of Leisure Research 39(2), 295-315.

Singleton, G. \& Linton, C. (2006). Courageous Conversations about Race: A Field Guide for Achieving Equity in Schools. Thousand Oaks, CA: Corwin Press.

Siwatu, K.O. (2011). Preservice teachers' sense of preparedness and self-efficacy to teach in American's urban and suburban schools: Does context matter?. Teaching and Teacher Education, 27(2), 357-365. http://dx.doi.org/10.1016/j.tate.2010.09.004

Skaalvik, E. M., \& Skaalvik, S. (2010). Teacher self-efficacy and teacher burnout: A study of relations. Teaching And Teacher Education: An International Journal Of Research And Studies, 26(4), 1059-1069. http://dx.doi.org/10.1016/j.tate.2009.11.001

Skaalvik, E. M., \& Skaalvik, S. (2007). Dimensions of teacher selfefficacy and relations with strain factors: Perceived collective teacher efficacy, and teacher burnout. Journal Of Educational Psychology, 99(3), 611-625. http://dx.doi.org/10.1037/0022-0663.99.3.611

Stone, D. N. (1994). Overconfidence in initial self-efficacy judgments: Effects on decidion processes and performance. Organizational Behavior and Human Decision Processes, $50(3), 452-474$.

http://dx.doi.org/10.1006/obhd.1994.1069

Taylor, A. \& Frankenberg, E. (2009). Exploring urban commitment of graduates from an urban-focused teacher education program. Equity and Excellence in Education, 42(3), 327346. http://dx.doi.org/10.1080/10665680903032344

Taylor, P.J., Russ-Eft, D.F., \& Taylor, H. (2009). Gilding the Outcome by Tarnishing the Past: Inflationary Biases in Retrospective Pretests. 30(1), 31-43. http://dx.doi.org/10.1177/1098214008328517
Temiz, T. \& Tupeu, M. S. (2013). Preservice teachers' teacher efficacy beliefs and constructivist-based teaching practice. European Journal of Psychological Education, 28, 14351452.

http://dx.doi.org/10.1007/s10212-013-0174-5

Tschannen-Moran, M., \& Hoy, A. W. (2007). The differential antecedents of self-efficacy beliefs of novice and experienced teachers. Teaching And Teacher Education, 23(6), 944-956.

http://dx.doi.org/10.1016/j.tate.2006.05.003

Tschannen-Moran, M., \& Hoy, A. W., \& Hoy, W. K. (1998). Teacher efficacy: Its meaning and measure. Review of Educational Research, 68, 202-248. http://dx.doi.org/10.3102/00346543068002202

U.S. Department of Education, National Center for Education Statistics, Schools and Staffing Survey (SASS), "Public School Teacher, BIE School Teacher, and Private School Teacher Data Files," 2007-08.

Vancouver, J. B., More, K. M., \& Yoder, R. J. (2008). Self-efficacy and resource allocation: Support for a nonmonotonic discontinuous model. Journal of Applied Psychology, 93(1), 35-47. http://dx.doi.org/10.1037/0021-9010.93.1.35

Vancouver, J. B., Thompson, C. M., Tischner, C., \&Putka, D. J. (2002). Two studies examining the negative effect of selfefficacy on performance. Journal of Applied Psychology, 87(3), 506-516. http://dx.doi.org/10.1037/0021-9010.87.3.506

Walker-Dalhouse, D., \& Dalhouse, A. (2006). Investigating White Preservice Teachers' Beliefs about Teaching in Culturally Diverse Classrooms. Negro Educational Review, 57(1/2), 6984.

Wheatley, K. F. (2004). The Potential Benefits of Teacher Efficacy Doubts for Educational Reform. Teaching and Teacher Education, 18(1), 5-22. http://dx.doi.org/10.1016/S0742-051X(01)00047-6

Wolcott, H. (1987). On ethnographic intent. In G. Spindler \& L. Spindler (Eds) (1987). Interpretive ethnography of education at home and abroad. Hillsdale, NJ: Elbaum.

Woolfolk, A.E., \& Hoy, W.K. (1990). Prospective teachers' sense of efficacy and beliefs about control. Journal of Educational Psychology, 82, 81-91. http://dx.doi.org/10.1037/0022-0663.82.1.81

Zach, S., Harari, I., \& Harari, N. (2012). Changes in teaching efficacy of pre-service teachers in physical education. Physical Education and Sport Pedagogy, 17(5), 447-462. http://dx.doi.org/10.1080/17408989.2011.582491

(c) 2015 Mucherah and Thomas; Licensee Lifescience Global.

This is an open access article licensed under the terms of the Creative Commons Attribution Non-Commercial License (http://creativecommons.org/licenses/by-nc/3.0/) which permits unrestricted, non-commercial use, distribution and reproduction in any medium, provided the work is properly cited. 